\title{
Teaching Death to Undergraduates: Exploring the Student Experience of Discussing Emotive Topics in the University Classroom
}

\author{
Natalie Pitimson \\ School of Applied Social Sciences, Brighton University, Brighton, United \\ Kingdom \\ N.Pitimson@brighton.ac.uk
}

The experience of learning about emotive topics in the classroom remains relatively underresearched. Within the social sciences death studies is undergoing a resurgence yet little is known about the student experience of exploring such issues in an academic setting. This research focuses on final year undergraduate students at a British university who have chosen to study a module on the Sociology of Death and Dying. Qualitative data from eleven semistructured interviews were analysed, revealing several key areas of experiential and pedagogical interest, highlighting how students use each other's experiences as well as their own vulnerabilities to engage with emotive topics. The data also explored the role of the tutor as an emotional safety net in such classes and the extent to which trigger warnings should be ensconced in university teaching. The emergent themes from these interviews are used to address the question of what are student perceptions of the experience and value of death education. They will also enable me to critically examine existing academic assumptions associated with dealing with emotive topics in the classroom and provide reflections on the extent of university's and lecturers' duty of care in such settings.

Keywords: death education; death; educational research; educational sociology; educator role; experience-based education 


\section{Introduction}

The purpose of this research was to explore the personal, emotional and pedagogical experiences of undergraduate students who have chosen to take a module about death and dying at university. Death is a sensitive subject to explore (Liamputtong, 2007), however Woodthorpe (2011) sees it as more extraordinary than other sensitive subjects, arguing that its universal nature makes everyone an insider when it comes to death. For students on death and dying courses the content is always personal (Watts, 2007) and it is considered good pedagogical practice for undergraduate social science students to reflexively use their reallife experiences to illustrate key concepts that they explore in class (Koster, 2011). However, a major unknown in any group of students studying such topics is the extent to which bereavement is a help or a hindrance in their learning processes - "For some, their own experiences of grief and loss may help...Others, however, may find their pain becomes obtrusive, and blocks their own, and others', learning processes" (Moss, 2000, p.206). This article explores the ways in which students use their own personal experiences and those of others to enhance their engagement with the material, as well as how feelings of vulnerability in the classroom can themselves be motivational learning tools. It also considers the debate around the use of trigger warnings in universities and the level to which the university or tutor is responsible for managing students' emotional experiences in the classroom and the impact this has on the kinds of teaching approaches that are enacted.

\section{Emotions in the Classroom}

A broad range of educational philosophies have accentuated the importance of emotion in learning, with students reporting that a classroom climate that elicits positive emotional 
experiences promotes greater personal involvement in learning (Naude et al, 2014). There is growing recognition of the central role of emotion in the classroom, yet it remains largely unexamined, with most research focusing on cognitive rather than emotional processes in learning (Naude et al, 2014). Learning is not unrelated to relationships and personal interests and intrusions into the private sphere need not always be threatening (Boud et al, 1993; Lee and Renzetti, 1993). Engaging with the taboo should not be beyond the capability of a university student. Death education courses invariably give rise to meanings linked to personal and contextual understandings of the topic (Watts, 2007) and it can be argued that issues such as bereavement are not so much private as they are emotionally charged (Lee and Renzetti, 1993). There is no reason to assume that discussions relating to death are inherently negative ones (Harrison, 2015; Baldwin, 2017), indeed Feifel (1963) suggested we feel less apart when we can share feelings and thoughts about dying and death.

However, experiencing emotion in the classroom has the potential to embarrass, transgressing as it does the 'rules' for appropriate behaviour in that setting (Hochschild, 2003). But learning and feeling should not be considered separate enterprises, particularly when engaging with potentially controversial or upsetting subject matters. Kalish (1981) makes the point that the purpose of death education is often seen to be either to reduce death anxiety $o r$ to simply increase factual knowledge, when in fact, he argues, it should really encompass both. Relatedly, Brina (2003) suggests that academia has its own norms and values that can interfere with critical and emotional engagement, meaning that whilst students may be happy to discuss intimate feelings with their peers, they are less comfortable doing so in academic spaces and that this embarrassment of students may be the quickest way to lose them and shut down further thought and discussion. She attributes this to the idea that by definition the academic and scientific seem to exclude the body and its feelings. 


\section{Changing Perceptions of Death Education}

Death education is a relatively recent phenomena, first emerging in the 1960s (Pine, 1977). Bregman (2008) attributes this emergence to the death awareness movement, whose aim was to use death education to change societal attitudes that maintained death as taboo - "the role of the death educator was to overcome silence and denial...to get the message across, that discourse about death was better than silence” (p.19).

Warren (1982) suggests that increasingly death education programmes work within an 'anxiety-reduction model', the aim being to "bring about comfortable interactions with death and dying as a personal reality" (p.17). More recently, Corr et al (2003) have outlined what they see as the four dimensions of death education. The first being that it is a cognitive enterprise, providing information about death-related experiences. Secondly, they speak of the affective dimension of death, that is, the feelings, emotions and attitudes about death and dying, considering too that some enrolled may have yet to encounter death themselves. Thirdly they argue that death has a behavioural dimension, exploring why people act the way they do in death-related situations. And finally, they speak of the valuational dimension, which relates to the ways in which learning about death can help to 'identify, articulate and affirm the basic values that govern human lives' (p.10).

Interestingly however, there are also concerns that death education itself can serve to contribute to broader death denial in society as it falls victim to trends towards its own narrowing and neutralisation. It is therefore increasingly the task of death educators to be mindful of delivering a 'searching encounter' with death rather than a 'comforting product' (Kastenbaum, 1977, p.85). Further, Kastenbaum makes the point that whilst it may seem increasingly anachronistic to speak of death as the taboo it was previously labelled, we should question to what extent the situation has really changed. Specifically, he questions 
whether death education is being exploited by society in order to serve as a more subtle form of denial, by shaping and presenting death in culturally convenient forms. To this end he suggests that much of society's response to the death awareness movement has actually been cosmetic rather than structural - "it strikes me that denial of death may be advancing toward a new level of sophistication,... we may be buying or selling acceptance only to become better deniers" (p.87). Kastenbaum bases his assertions on the idea that knowledge is a key way in which anxiety can be reduced and control gained, but that the process of this can lead to focusing on what is easy to study rather than what is critical or distinctive: "Death has not necessarily become an object of careful consideration in death education... The death educator may drift unwittingly towards... those messages that win quick approval, instead of the longer, harder inquiries that fail to resolve anxiety on immediate demand" (p.90/91). He argues that once death becomes a topic on the syllabus, an item on the timetable, it then correlates with more familiar experience that is almost reassuring in its routine nature, allowing students to accept what is convenient to take in about death but deny that which is difficult to face, death as absence, death as annihilation.

Nevertheless, it has been increasingly argued that to study death and dying is to face some of the most profound questions confronting human beings (Corr et al, 2003) and that therefore death, dying and bereavement should be an essential component of education (Corr and Wass, 1992). Resistance to this view could be due to common misunderstandings of what is taught in classes on death and dying, with Corr (2016) suggesting that people who have not taken such a module may harbour misconceptions of what the content is, believing that it contains morbid, depressing, taboo material that is a peculiar and inappropriate choice for 'innocent young people'. However, he argues, such topics are in fact vital and to believe we 
could have a realistic examination of human life without including death is to bury one's head in the sand.

\section{The Role of the Educator in the Teaching of Controversial Issues}

Hess (2008) makes the point that even though there is evidence that participating in discussions of controversial issues has positive outcomes, it is important to recognise that classrooms are complicated spaces that are experienced in different ways by the students in them. The subject of death sits at the nexus of the emotional and the controversial, placing the educator in a reasonably unique position, addressing classroom management and care issues across a broad spectrum of pedagogic challenges. Controversy tends to arise when topics can be personalised by students and knowing what subjects may impact on students in such a way may not always be predictable (Burkstrand-Reid, Carbone and Hendricks, 2011). Differing views and experiences related to death can provoke extremely diverse and powerful responses, requiring the educator to exercise sensitivity and control but in such ways that also do not inhibit constructive reflections. In this way then, Hickey (2016) argues that educators often serve as the first line of defence, especially when it comes to identifying students who are experiencing stress or anxiety.

Bregman (2008) suggests that students may view a class on death and dying as a safe space to discuss their own experiences of loss and therefore death education tutors are required to"'honour' these experiences and consider them potentially part of the students' education" (p.25). For Bregman, to honour in this context requires that instructors find ways to allow academic space for the most upsetting of disclosures. However, he also makes the important point that whilst students may bring profound emotional experiences to the course, it is not the role of the tutor to intentionally provoke these. Indeed, Lusk and Weinberg (1994) suggest that instructors instigating discussions on controversial topics is one thing but forcing 
students to talk about these issues is another. Conversely, Lieb (1998) argues that it is not necessarily wrong to make students feel uncomfortable, indeed he suggests that provoking uneasiness challenges students to look at and experience the world in new ways, something he sees as the duty of educators. He does though concede that whilst dynamic discussions may ensue from such pushing, there is potential for disruption and upset to other students too. Therefore, he reminds us that whilst not to be discouraged, the issue of how a tutor handles controversial topics in the classroom remains a delicate one. Yet, such topics are part of society, are often in students minds and may well be a part of their experiential biographies and do therefore have a meaningful place in the classroom (Lieb, 1998).

\section{Methods}

The focus of this research is a third-year undergraduate option module I teach called 'Death and Society' that students from a range of social science degree courses have the choice to enrol on. I sent an email to all registered students a month after they had completed the module, asking them if they would like to participate in the project ( $n=11$ : female $n=9$, male $n=2$ ). Semi-structured interviews were carried out by me and these were then transcribed by an external agency. My research design was informed by existing guidance on researching sensitive topics. Elam and Fenton (2003) state that qualitative approaches and semi or unstructured interviews in particular are best suited to researching sensitive topics and I chose to conduct the interviews myself as opposed to delegating to my research 
assistant, who is unknown to the students, as we had shared the classroom experience of learning about these ideas and built up a rapport and known way of exploring such issues together. This in turn helped to contribute to the creation of a non-threatening environment that Karnieli-Miller et al (2009) argue is so important if participants are to willingly share their personal experiences and beliefs. As mentioned earlier, areas such as death and dying are not so much private as emotionally charged and it could therefore be argued that the choice to take part in such research by participants reveals a desire for catharsis rather than sanctuary (Lee and Renzetti, 1993).

Data analysis was carried out through a general inductive approach, which here was taken to be defined as an approach that primarily uses:

Detailed readings of raw data to derive concepts, themes, or a model through interpretations made from the raw data...to allow research findings to emerge from the frequent, dominant, or significant themes inherent in raw data, without the restraints imposed by structured methodologies (Thomas, 2006, p.238).

Following this approach, the transcripts were read several times by me and emergent themes were recorded which were then collated into key themes. These then formed the subcategories of the following sections. To protect their anonymity participants' names have been replaced with codes such as A1or S2.

Ethical approval was obtained from the School of Applied Social Sciences ethics committee at the University of Brighton and the project was funded by the Centre for Learning and Teaching at the University of Brighton. 


\section{Findings}

\section{Motivations for studying death}

I began my discussions with my participants by asking them to reflect on their motivations for wanting to study death. Their responses varied from curiosity to wanting to understand personal experiences in greater depth to feeling safely distant enough from the subject matter to assume it would only be interesting and not upsetting. A1 entered the module with an existing positive attitude towards death and dying:

I chose it because I personally don't deny death, I'm not scared. ...I'm actually kind of excited to see what is to come after this life, I had a near death experience from a car accident five years ago, so I did face death and the fact that it didn't scare me and even though my body was all crushed...I had so much mental strength because I wanted to live and be a teenager...so for me to learn about it is really interesting.

Early meditations on the concept of dying were also key to A2's motivation for choosing the topic:

When I was younger I did actually have very bad anxiety and death was brought up to me a lot then, I had a lot of existential dread and crisis around death and I suppose that made my interest grow within it...like if someone has received [sic] like homophobia then they might be really interested to see why that would happen, it's kind of the same with me and death really.

A3's motivation is perhaps best described as a desire to explore the academic unknown: 
I expect to be taught about things that are comfortable topics ... things that are socially acceptable, death is interesting because nobody really talks about it. Like, everybody knows they are going to die but I guess I'd never really thought about it until there was the option to study it.

S3 had yet to experience loss and therefore felt the topic would be objectively interesting but not something she would experience much of an emotional response to: "I just thought it would be interesting and stuff, there's never really been any deaths in my family or friends or anything like that so...I don't have any feelings or memories to draw on yet”.

\section{Teaching Approaches and Knowledge Boundaries}

When designing the module I made the decision to deploy a more 'traditional' structure to the classes, that being a lecture, followed by a seminar based around questions and readings supplied by me. This was because I felt it was important to contain the knowledge as best as possible in order to help the students to feel as safe as they could whilst exploring these ideas. However, at a time when ever more creative and student led teaching approaches are emerging as popular pedagogical styles within the social sciences I wanted to explore my participants' views on the application and usefulness of such methods in the classroom when teaching death and dying. Reflecting on the possibility of more creative teaching approaches, A3 said:

I feel like if it's a sensitive topic like death...you run a risk of it becoming...not as controlled...I feel like when it's make a poster or be a bit more creative, a bit more like freedom, it can become a bit more uncomfortable. 
Similarly, reflecting on approaches to teaching about suicide as a topic, S3 said "I think especially if it's such a sensitive topic I don't think many people would be into doing role play and things like that because it could spark memories", S1 agreed with this sentiment, stating "definitely when it comes to death then I think it's better to keep it controlled... because I think things can just get like just too twisted and overlapped”.

However, whilst a preference towards slightly more restrained teaching methods was apparent, it was conversely felt that there should be no boundaries regarding what subject matters can actually be covered in the classroom, there was a particularly strong shared belief that sociology, by its very nature, should have no topics off limits to it:

I think in sociology you have to learn about everything from rape to child soldiers...I think it's all important to talk about and I think people know that when you come into a...sociology degree...you can’t learn about everything nice and nothing bad cos that's not what sociology is (S3).

Whilst they did feel some topics were certainly more difficult than others to confront in a classroom setting, this did not diminish their belief in the need to do so, for example, A2 reflected on the experience of learning about suicide on the module:

Before I'd have probably thought that suicide might have been a topic which just really don't talk about [sic], but then again it is actually important and has a lot of place in theory and in so many topics...I think if I can learn about that then I can't really see there's any other boundaries.

Similarly, A1 said - "I think as a sociologist we have to be open...and opinionated...I think there's no room for uncomfortableness with sociologists". A1's belief in the need for sociological education to be as broad as possible was typical of many of the responses of others too: 
I feel like if someone wants to learn it and someone's prepared to teach it it should be taught...obviously we should never be taught how to like build a bomb or like to kill and stuff but I feel like on an academic level if someone want to learn about rape or someone wants to learn about sexual violence or death or terrorism... ...then I don't really see as an issue [sic], as long as they know what they're signing up for.

This was important for a lot of participants, to 'know what they are signing up for'. This therefore led to a more detailed discussion around emotional labour and vulnerability in the classroom as well as the place of trigger warnings in an academic context.

\section{Vulnerability, Emotional Labour and Trigger Warnings in the Classroom}

The issue of vulnerability was one that all the participants brought up as a key element of their classroom experience when learning about death and dying. Importantly though, this was not always experienced as a road block in their learning, rather at times a heightened emotional experience in response to a set of ideas had also served to enhance their engagement with the material being discussed. Participants seemed to accept the risk of being made to feel vulnerable if they believed the tutor still had ultimate control of the situation. A3 recalls a discussion around a topic that had elicited feelings of vulnerability in her:

I felt very vulnerable with my own personal experiences of it and I just wanted to get up and leave...But at the same time sitting there and learning about it and facing it...I think sometimes feeling vulnerable is a good thing...the vulnerable situations are always going to be there when you talk about sensitive topics but I feel like they help your understanding of the topic as well. 
This was a common thread amongst the participants and suggests that allowing students to experience knowledge in a visceral way rather than protecting them from such an experience, can at times be a productive pedagogic exercise. A2 points to the powerful impact that vulnerability can have:

If I feel vulnerable with a topic I want to know more about it. So I then choose to do my essay on it to challenge any vulnerabilities I have with it... I would have said I was very denying of death before I started the module and I just never wanted to talk about it ...so I then chose to...focus on that and do my essay on that...for me I want to know everything about it and it really engages me more because that vulnerable feeling [sic], I want to push through it.

S1 reflected similarly:

I know if I just get up and leave or don't talk about it then next time I'll just feel vulnerable again, whereas if I like sit and discuss it and have a conversation then that vulnerable feeling's gone and I feel a bit more at ease and I'm actually really interested in it.

Interestingly, S2 reflected on the root of the why students choose to do topics they know have the potential to make them feel initially ill at ease:

You know if you're going to feel vulnerable about a topic or if you know a topic is slightly sensitive, it kind of makes it more interesting. It's like that weird sadistic like this is a taboo subject [sic]... therefore I want to know everything there is to know...they make people feel vulnerable but why do they make people feel vulnerable? I want to know everything I can.

Experiencing, taking control and channelling feelings of vulnerability is an act of educational empowerment for these students. 
It became apparent too from these discussions that many of them were engaging in a degree of emotional labour in the classroom. It should be noted that I use this phrase to refer to the processes inherent in managing, filtering and controlling one's emotions in specific contexts, but with the purpose of maintaining social capital rather than the economic capital that Hochschild (2003) privileged in her description of it. Many of the participants made it clear that they engaged in a 'project' of managing their emotions in the death classroom:

I'm very careful with who I show my emotions to, that's something that I've learned over time... there are personal experiences about death and things that even like my friends don't know about...I think leave your emotions at the door and kind of get into a learning mode (S1)

Though not as severe as S1, S4 made clear that the need to retain an amount of social capital led to him exercising a degree of emotional distance in the classroom: "I did think a few times I wanted to bring up my experiences but obviously it's difficult to bring things like that up ...because it kind of changes the way people see you". Similarly, A5 reflected on her perception of the consequences of overly emotional disclosure in the classroom:

I've always had the feeling that people think that you want them to feel sorry for you but it's not like that at all, it was hard for me to speak about it for so long [the death of a close friend] and I finally spoke about it [in class] but I held back a lot of the details that meant more to me, to protect me and her [the friend she lost] I guess

Existing classroom relationships also played a part in the degree to which students engaged, S6 described how she consciously disconnected from the discussions around suicide because she feared the emotional upset the topic would cause a fellow student:

I have a friend that did try at university to commit suicide... and she was in the death lecture and I felt I couldn't put anything across in the right way so I wouldn't want to 
say anything because then I would be hurting her feelings... so that's why I like never really spoke about it or really went into the topic just because I didn't want to... let it affect the friendship in any way.

Again, what S3 is describing here are her concerted efforts to disengage from a topic to maintain an important social relationship. The bigger picture of the interconnections between a student's academic engagement and their emotional and social ties with other students in the room should not be overlooked when exploring the student experience of learning about emotive topics. Interestingly, whilst most commonly students reflected on experiences of emotional labour in terms of holding back contributions, A4 reflected on her emotions following what she felt was a particularly 'risky' disclosure about her spiritual beliefs:

The one time I felt a bit awkward or embarrassed was when I was expressing my spiritual stuff ... because I can feel people's energies, so I could feel some people were like really intrigued but I could feel some people were like, oh wait a minute, is she crazy...I can be quite a shy person around people I don't really know very well...so I tried not to be but when [something like that happens] it kind of makes you shut down a little bit.

\section{Learning Through Personal Experience, In and Out of the Classroom}

Despite some participants actively choosing to hold back on personal engagement at times, a common theme arising too amongst other participants was the way in which discussing personal experiences of the issues being explored helped them to better engage with the 
relevant academic material, both in terms of talking about their own experiences and hearing those had by others:

People are willing to talk about it. You didn't even ask and people were like, oh this is my experience and I think it's really important to hear other people's experiences because you can learn from that ...we're here to learn and I think the best way to learn is from experiences and especially from other people (A1).

A3 made specific links between her ability to understand theoretical work and hearing about other students' experience of the ideas being discussed:

I feel like it helps to underpin the theory and the academic side when someone's like 'in my experience'...it definitely helps me understand something more when I can relate it to my own life or people my age's life...it makes it more relatable...because people my age have experiences with it. It's not just something that happens to other people, it happens to people I'm sharing a classroom with

This comment highlights one of the key issues in the teaching of death and dying, the disconnect students can sometimes feel with the ideas being discussed, their age making their own death unthinkably distant and perhaps having yet to experience close personal loss of any sort. Hearing the narratives of those who, by the same age, have had such experiences, allows them to be more closely drawn into the subject. Interestingly, A2 felt that having experience of an issue being discussed was so important that to not have done so meant he would not contribute to classroom discussions

[referring to a discussion about online grieving] I wanted to say something but I didn't... when they are saying things which are very much about their specific experiences I feel like I can't really put my opinion in for that when I haven't had an experience, but I think that's right. 
Some, however, did not see the relevance or merit of other students sharing their personal experiences, instead seeing this as risky behaviour and likely to disrupt the class:

I just think things can get like too deep...I remember one of the students shared a story about her daughter recently attempted suicide [sic]... and I was literally like oh my, and the whole room just fell silent because no one wanted to talk about it. No one wanted to say well Durkheim would say that your daughter did this because blah blah [sic]... so I think it's just better not to personally (S1)

S1 further discussed how she tended to switch off when students were sharing personal anecdotes because in terms of learning she said: "it's not what it's about...I am not here to listen to X's story who I don't know cos it's not going to benefit me, it probably won't benefit a lot of people in the room". Some also expressed concern as to the potential harm such personal disclosure in the classroom could cause to individuals, as A2 reflects - "I think that's a good thing [sharing personal experiences] but...if you're going to talk about death and yeah and it is really personal to you or if you're still getting over grief then obviously...it would be quite detrimental to some people...it's kind of up to the individuals...because they're the only ones that know themselves how far they can go with certain things". Similar conversations with other participants led too to a reflection on how responsible they felt the tutor was for protecting students during such discussions. There was a common held belief in personal accountability regarding emotional well-being in the classroom but this was often largely predicated on the assumption of ultimate tutor care and responsibility, so whilst personal responsibility and agency do exist in this context, because of the subject nature such concepts remain ultimately tethered to the tutor. As A2 expounds:

There's only so much that you [the tutor] can do...just kind of reminding them about the sensitivity of those subjects... there's only so much responsibility you have for 
protection of students because every single person is a very different individual...but I guess I do hold you in a matriarchal role in that class and that does make me feel safer when I need it.

A3 had similarly conflicting views on the extent of a tutor's responsibility in this context:

I feel like we have more of a duty of care to protect ourselves, so if you don't want to learn something you don't have to turn up, and if you feel uncomfortable you can leave...I would never want to say something intentionally to hurt other people but I do know if I do then you are there to fix the mess!

S3 had a slightly more dismissive view of the tutor's role, seeing it mainly as that of facilitator, however she still ultimately rests this on the principle that there is assumed responsibility for well-being during difficult discussions on the part of the tutor:

I never really think about it [the tutor's role] because like at the end of the day it's like just education, you are here to learn, that's what you are doing and obviously the tutors are going to care about your well-being and things but I don't think it's that important.

It is clear therefore that attaching experience to discussions, whether their own or others, is an important way in for some students when discussing emotive topics but confidence and ease of doing so rests on the assumption that the tutor is 'obviously' always 'looking after' them.

Often when leaving the classroom and following students down the corridor at the end of sessions I was able to overhear their discussions about topics continuing. This interested me in terms of what, if anything, these post-class discussions added to the student learning experience and if they were in some way qualitatively different to those they may have had after classes that covered less emotive topics. It became apparent from my participants that this subject matter in particular led them to more extensive, reflective and often philosophical 
discussions with a broad range of people outside of class and that this in itself was a productive and valuable 'hidden' form of education. As A1 explains: "Especially with death, I definitely taught my parents a lot of the material that I learnt and my boyfriend...explaining it and then debating it". Similarly, A3 described how the processing of lecture material and ideas can go on well beyond the end of the session itself:

Because I think that if I go away and talk about it with my friends and they've taken something different from it, I've then learnt a different perspective, I think 'oh actually I didn't think of that' and even if it's just that five minute conversation, even if it's not academic I've learnt that they feel this about death, whereas I feel like this... by continuing the conversation over the day, the week, I almost become immersed in it...you go from having two hours of knowledge with you to having like five hours with your friends as well

Indeed, A3 found herself becoming something of an advocate for 'death positivity' amongst her housemates - "After your class I would talk to my housemates and I'd notice that they were a bit more uncomfortable and I'd be like 'no it's fine', I think more people talking about it makes it less scary".

I also wanted to garner the participants' views on trigger warnings on the module, at present the content for each session is available a week before and information about elements that may have the potential to trigger upset or discomfort is flagged at the top of the online content folder, students are told that they do not need to attend if they feel content may be too upsetting or act as a trigger for them. This is a personal initiative rather than a directive from my department but there are emerging debates around the place and impact of such warnings within universities. Most students saw the merits of them, though some were a little more lukewarm regarding their usefulness. A1 felt students should receive an overview of such 
warnings for the entire module at the start of it: "because if it is going to come up that is an uncomfortable topic [sic] then I think the students should know about it in the first lecture". A2 had a similar attitude: "I do think that's definitely $100 \%$ a good thing, just because it upsets me the idea of some people that could [get upset] ...even if it's just silly it's better safe than sorry isn't it really?". Though this was indicative of the most common sentiment, it was not shared by all. A3 reflected on the fact that such warnings have the potential to go too far and that a degree of agency and personal responsibility should really be enacted by students when choosing what to study:

You know there's going to be trigger warnings when you pick a module like death...like in reality then the whole module would have a trigger warning and then that just becomes a bit insane...like you're doing a module about death, of course we're going to talk about people dying...if it was a module in which everything was sunshine and roses and then there was one week that just wasn't, then that's fine, trigger warning that week, but with a whole module, it's literally titled Death and Society, you have to think you kind of know what you're getting yourself in for.

\section{Discussion of Findings}

\section{Teaching Approaches}

To discuss death is not an easy thing to do and there are issues associated with making pedagogy painful. In a society habituated towards evading thoughts of mortality, confronting it in a classroom has the potential to lead to an unsafe and uncomfortable learning space for 
both teacher and learner (Affifi and Christie, 2018). Consideration of teaching approaches and styles is therefore of crucial importance. These students valued stronger, more instructive parameters when learning about emotive topics. They still felt able to explore the process of meaning making whilst in a relatively controlled classroom environment and indeed in the case of more emotive topics, preferred to. It is not the case that students only feel safe in environments that they themselves direct, nor is it the case that such student led environments are the only ones that foster creativity and intellectual curiosity.

Regarding the place and importance of students' own experiences in the classroom, it is only relatively recently that it has started to be argued that education needs to turn back to the world of experience. Weimer (2013) describes contemporary university students as dependent learners who would rather not speak in class and for whom education is "something that happens to them" (p.88). In order to counteract student passivity, bell hooks advocates specifically for engaged pedagogy, that is, a pedagogy that values student expression, one that respects students' needs to speak about their experiences in the classroom and one which understands the relevance of these experiences to their learning process $(1994$, p.21). She emphasises the need to see students as whole human beings who enter the classroom embodying complex lives, rather than just as individuals seeking compartmentalised knowledge. For hooks therefore, linking formal discussion to social reality is a process that acknowledges learners as a "source and bearer of knowledge" (Florence, 1998 p. 103).

The traditional 'transmission' approach to learning is generally depicted as existing in opposition to the social constructivist approach. The former rests on ideas of knowledge being a fixed body of information, the teacher as the authoritative source and students simply replicating what has been explained. The latter meanwhile is more concerned with the ways in which learning depends on students' existing understandings, as well as the idea that social 
interaction plays a critical role in the ways in which learners construct their own learning (Brophy, 2002). What has been demonstrated by my participants is the preference, when dealing with emotive topics, to treat the relationship between these two approaches as more of a continuum than a dichotomy, from a fairly rigid base of information and teacher led parameters, they then feel able to go further and integrate their personal experiences and/or those of others into their learning and meaning making processes. Naude et al (2014) make a link between Vygotsky's social learning theory and feminist epistemologies, viewing learning as a social practice in which the teacher becomes decentred. Again, this is neither the experience nor the desire of the participants in this study. However, as noted above, the topics were often the subject of conversation with other students, as well as friends and family, after they had left the classroom. This echoes Vygotsky's ideas (cited in Naude et al, 2014) that higher education may include a variety of interactions and furthers the argument that learning should be conceptualised not only as a cognitive or affective issue but should also include considerations of social engagement. This links with ideas too around peripheral student dialogue that occurs particularly when dealing with controversial topics: "Whilst the issues are provocative, some students remain silent and do not participate in the formal class setting; they hold back their comments for a less exposed moment" (Housee, 2010, p.421). This can be understood as a process of participatory pedagogy, that is, processes that emphasise the social nature of teaching and learning as well as the idea that the pedagogical process is essentially a process of social interaction (Niemi, Heikkinen and Kannas, 2010). This is particularly pertinent when studying a topic such as death: "For students enrolled on death education courses, death and dying is always personal... abandoning either the personal...or the social diminishes the strength of explanation and can only result in a reductionist perspective on these issues" (Watts, 2007: p.270). Alongside this, however, and as reflected on by some of my participants, Lusk and Weinberg (1994) highlight that students' concerns 
about their social relationships with their peers may take precedence over concerns about their role in the class and may therefore make them reluctant to speak for fear of jeopardising such relationships. They argue therefore that it is vital to help students to break down the connection between 'disagreement' and 'dislike' in their classroom interactions with their peers.

\section{Emotional Labour in the Classroom and Tutor Responsibility}

We should not be afraid of emotional disclosure in the classroom. However, it should also be noted that at such moments of disclosure relationships within the classroom can change as the learning journey becomes a more emotional one (Koster, 2011). Therefore, education should not be thought of as a disembodied experience and in describing how they appropriate feelings of vulnerability into motivation to explore an issue further, these participants demonstrate that in fact when dealing with such topics, the emotional is at the very centre of their learning processes.

Corr (2016) makes the point that given the many different reasons as to why a student may have chosen to study death, it is incumbent upon the instructor to be sensitive to their differing concerns and needs. When we encounter students in higher education we obtain only a glimpse of their lived realities as individuals who are involved in complex processes of learning and development (Naude et al, 2014). No consensus exists for what constitutes sensitivity, indeed the term 'sensitive topic' is often used as if it were self-explanatory and has increasingly become synonymous with the controversial when in fact it is possible for any topic to be a sensitive one (Lee and Renzetti, 1993). Leslie and Hutchinson (2018) describe student responses to sensitive topics as encompassing a range of emotions, including fear, discomfort and anxiety. However, as Barnett (1997) says, an education that is 
comfortable and 'risk-free' may also then fall short of actual critical academic development. Against this backdrop, the extent to which tutors in higher education can be expected to offer pre-emptive emotional support continues to be a contested issue but given the nature of death and dying education, some amount of emotional support should be expected of lecturers (Watts, 2007).

Recently there have been increased debates around the use of trigger warnings in academia. Taylor (2017) outlines the debate as existing between those in favour of them, who liken their use to standard content prefaces that warn media content could be deemed offensive, versus those who argue that the academy should be an exception to such warnings and that in order to preserve intellectual exploration higher education should not be subjected to the same rules as the media. Thus, finding a comfortable stance between maintaining the welfare of students and censorship of the curriculum is increasingly less straightforward. Nevertheless, Colbert (2017) makes the point that it is important to find a way to strike this balance. The purpose of trigger warnings, he explains, is to give students who may have a negative response to content the opportunity to better prepare themselves to engage with potentially triggering materials, rather than avoid them altogether. I agree with Colbert, trigger warnings are not an exit door, rather they give students agency over levels of engagement with the material they are being presented with and serve to promote equality of access to education : "trigger warnings are not about removing words, ideas, and subjects from the syllabus...[they] are not about what we teach; they are about how we teach" (Stringer, 2016, p. 63). Therefore, regarding a tutor's duty of care when teaching difficult or emotive topics, providing clear and timely trigger warnings pose little harm when applied to students who don't need them, yet offer significant benefits to those who do (Taylor, 2017). 


\section{The Role of the University in the Safety and Protection of Students}

Such considerations of trigger warnings bring us to a final broader consideration of the role the university has or should have in ensuring the safety and protection of its students in educational spaces and what this means for the inclusion of difficult or emotive topics on courses.

The issue of the university as a 'safe space' has come under the spotlight recently not least because of the letter written by John Ellison, the university of Chicago's dean of students, in 2016 - “Our commitment to academic freedom means we don't support so-called 'trigger warnings', we do not cancel invited speakers because their topics might prove controversial and we do not condone the creation of intellectual 'safe spaces' where individuals can retreat from ideas and perspectives at odds with their own" (cited in Palfrey, 2017.p 23). The key issue here is that the debate around the university as a safe space focuses on the one side on those who believe such notions are a sign of 'coddling' students, as opposed to others who believe safe spaces to be an essential element of campus life. In fact, Palfrey argues, it should be the case that universities provide students with both safe and brave spaces in which to learn: "brave spaces are environments where students are encouraged to engage in serious, respectful, and empathetic discourse as part of their education. Campuses at large need to remain places where students learn to confront the uncomfortable and the unfamiliar and respond in ways that enable them to grow" (Palfrey, 2017.p.31). I contend therefore that it is necessary for universities and the educators within them to create spaces where students feel both safe and emboldened to engage in challenging discourse. As several of my participants noted, the fact that a topic is difficult to discuss should not mean it gets left off the syllabus: "Since part of the job of schools and universities is to prepare students for the world outside academia, it would be a terrible mistake...to create a false environment in which students never experience or endure discomfort of any kind” (Palfrey, p.33). 
It is important then to characterise the kind of space a university is in the context of safety and protection. I argue, borrowing language from urban sociology, that it is a relational one. Butler et al (2017) define relational space in an educational setting as "space as constituted by the various relationships between and among all the entities therein...All of these relationships are in flux, creating a space that is constantly shifting” (p.897). One group, one semester, may elicit very different classroom environments, expectations and interactions around controversial topics. 'Safe Space' therefore, in the context of the university, should be understood as flexible space, that maintains a constant state of fluidity in order to always be well-situated to facilitate a student experience that is both safe and empowering for each unique cohort.

\section{Conclusion}

Future research in the field of teaching emotive topics should consider a closer engagement with the ways in which notions of 'positive vulnerability' may inform pedagogic design and decision making in the development of emotive curricula. It can never be known what experiences every student has had when they arrive in the classroom. But fundamentally, learning about death and dying is teaching us too about life and living. By examining death, individuals are given the opportunity to develop a greater understanding, appreciation and reverence for life, legitimising one's inner feelings towards death whilst placing the experience of the dying within the natural realm of human experience (Eddy and Alles, 1983). The less death is hushed up, the less likely people are to retreat from it when so confronted (Affifi and Christie, 2018). 
This work was supported by the Centre for Learning and Teaching at Brighton University.

Word count (excluding reference list $)=7995$.

\section{References:}

Affifi, R., and Christie, B., (2018) 'Facing loss: pedagogy of death' Environmental Education Research DOI: 10.1080/13504622.2018.1446511

Baldwin, P.K., (2017) 'Death Cafes: Death Doulas and Family Communication' Behavioural Sciences 7 (2). 26.

Barnett, R. (1997) Higher Education: a critical business. Buckingham: Open University Press.

bell hooks (1994) Teaching to Transgress: Education as the Practice of Freedom London:

Routledge

Boud, D., Cohen, R., and Walker, D., (1993) 'Introduction: Understanding Learning from Experience' in Boud, D., Cohen, R., and Walker, D., (Eds) Using Experience for Learning Buckingham: Open University Press.

Bregman, L. (2008) 'What Should a Course on Death and Dying Accomplish? "Death Education" in an undergraduate Religion Course" in Morman, C.M. (Ed.) Teaching Death and Dying Oxford University Press. pp: 17- 32.

Brophy, J. (2002) 'Introduction' in Brophy, J. (Ed.) Social Constructivist Teaching:

Affordances and Constraints. Oxford: Elsevier. pp: ix - xxii.

Burkstrand-Reid, B., Carbone, J., and Hendricks, J.S. (2011) 'Teaching Controversial Topics' Family Court Review 49:4. pp:678-684. 
Butler, J.K., Kane, R.G., and Morshead, E. (2017) '”It's My Safe Space"': Student Voice, Teacher Education, and the Relational Space of an Urban High School' Urban Education 52:7. pp: 889-916.

Colbert, S. (2017) 'Like Trapdoors: A History of Posttraumatic Stress Disorder and the Trigger Warning' in Knox, E.J.M (Ed.) Trigger Warnings - History, Theory, Context London: Rowman \& Littlefield. pp:32 - 75 .

Corr, C.A. (2016) 'Teaching About Life and Living in Courses on Death and Dying' Omega - Journal of Death and Dying 73:2. pp: 174-187.

Corr, C.A., Nabe, C.M., Corr, D. (2003) Death and Dying/Life and Living Fourth Edition. London: Thomson Learning.

Corr, A., and Wass, H. (1992) 'International Work Group on Death, Dying and Bereavement. A statement of assumptions and principles concerning education about death, dying and bereavement' Death Studies 16. pp: 59-65.

Eddy, J.M, and Alles, W.F. (1983) Death Education Mosby.

Feifel, H. (1963) 'Death' in in Farberow, N.L. (Ed.) Taboo Topics New York: Atherton Press. pp: 8-21.

Florence, N. (1998) bell hooks' Engaged Pedagogy: A Transgressive Education for Critical Consciousness London: Bergin and Garvey.

Harrison, N. (2015) 'Positive death: the third wave' Lancet Oncology 16:6.

Hess, D. (2008) 'Controversial Issues and Democratic Discourse' in Levstik, L.S. and Tyson, C.A. (Eds.) Handbook of Research in Social Studies Education London: Routledge. pp: 124135. 
Hickey, J. (2016) 'Exempting the University: Trigger warnings and intellectual space' First Amendment Studies 50:2. pp: 70-82.

Hochschild, A.R. (2003) The Managed Heart-Commercialization of Human Feeling Berkeley: University of California Press.

Housee, S. (2010) 'When silences are broken: an out of class discussion with Asian female students' Educational Review 62:4. pp:421-434.

Kalish, R.A. (1981) 'Death, Grief and Caring Relationships’ Brooks/Cole Publishing Company.

Karnieli-Miller, O., Strier, R., And Pessach, L. (2009) 'Power Relations in Qualitative Research' Qualitative Health Research19:2. pp: 279-289.

Kastenbaum, R. (1977) ‘We Covered Death Today’ Death Education 1:1. pp: 85 - 92. Koster, S. (2011) 'The Self-Managed heart: teaching gender and doing emotional labour in a higher education institution' Pedagogy, Culture and Society 19:1. pp: 61-77.

Lee, R.M and Renzetti, C.M. (1993) 'The Problems of Researching Sensitive Topics: An Overview and Introduction' in Renzetti, C.M. and Lee, R.M. (Eds) Researching Sensitive Topics London: Sage. pp: 3-13.

Leslie, C., and Hutchinson, A.D. (2018) 'Emotional distress when studying sensitive topics in psychology, and its relationship with hardiness and mental health' in Higher Education Research and Development.

Liamputtong, P. (2007) Researching the Vulnerable: A guide to sensitive research methods London: Sage. 
Lieb, J.I. (1998) 'Teaching Controversial Topics: Iconography and the Confederate Battle in the South' Journal of Geography 97:4-5. pp: 229-240.

Lusk, A.B. and Weinberg, A.S. (1994) 'Discussing Controversial Topics in the Classroom: Creating a Context for Learning' Teaching Sociology 22:4. pp: 301-308.

Moss, B.R. (2000) 'Death studies at university: new approaches to teaching and learning' Mortality 5:2. pp: 205-214.

Naude, L., van den Bergh, T.J., I.S Kruger (2014) 'Learning to like learning': An appreciative inquiry into emotions in education' Social Psychological Education 17 pp: 211228.

Niemi, R., Heikkinen, H.L.T., and Kannas, L. (2010) 'Polyphony in the classroom: reporting narrative action research reflexively’ Educational Action Research 18:2. pp: 137-149.

Palfrey, J. (2017) Safe Spaces, Brave Spaces London: The MIT Press.

Pine, V.R. (1977) ‘A Socio-Historical Portrait of Death Education’ in Death Education 1:1. pp: $57-84$.

Taylor, H. (2017) ‘Accessibility on Campus - Posttraumatic Stress Disorder, Duty to Accommodate, and Trigger Warnings' in Knox, E.J.M (Ed.) Trigger Warnings - History, Theory, Context London: Rowman \& Littlefield. pp: 76-110.

Thomas, D.R. (2006) ‘A General Inductive Approach for Analysing Qualitative Evaluation Data' American Journal of Evaluation 27:2. pp: 237-246.

Warren, W.G. (1982) 'Personal Construction of Death and Death Education' Death Education 6:1. pp: 17-28. 
Watts, J.H. (2007) 'Locating the 'I' in the teaching of death and dying: challenges of the open distance learning model' Open Learning 22:3. pp: 263-271.

Weimer, M. (2013) Learner-Centered Teaching - Five Key Changes to Practice. Second Edition San Francisco: Jossey-Bass.

Woodthorpe, K. (2011) 'Researching death: methodological reflections on the management of critical distance' International Journal of Social Research Methodology 14:2. pp: 99-109. 